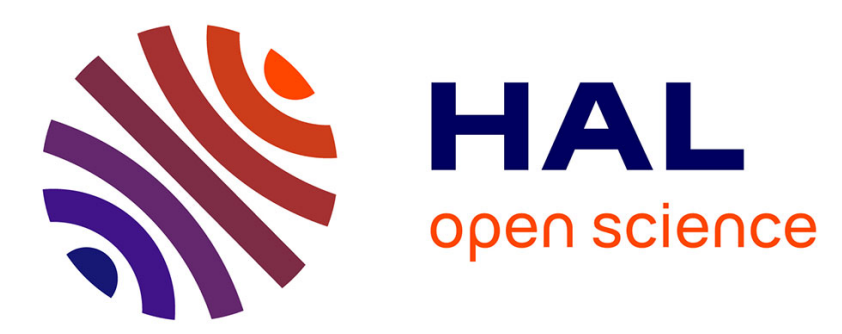

\title{
Lagrangian-based Simulations of Hypervelocity Impact Experiments on Mars Regolith Proxy
}

\author{
M. Froment, E. Rougier, C. Larmat, Z. Lei, B. Euser, S. Kedar, J. E \\ Richardson, T. Kawamura, P. Lognonné
}

\section{- To cite this version:}

M. Froment, E. Rougier, C. Larmat, Z. Lei, B. Euser, et al.. Lagrangian-based Simulations of Hypervelocity Impact Experiments on Mars Regolith Proxy. Geophysical Research Letters, 2020,47 (13), pp.e2020GL087393. 10.1029/2020GL087393 . hal-02975098

\section{HAL Id: hal-02975098 \\ https://hal.science/hal-02975098}

Submitted on 22 Oct 2020

HAL is a multi-disciplinary open access archive for the deposit and dissemination of scientific research documents, whether they are published or not. The documents may come from teaching and research institutions in France or abroad, or from public or private research centers.
L'archive ouverte pluridisciplinaire HAL, est destinée au dépôt et à la diffusion de documents scientifiques de niveau recherche, publiés ou non, émanant des établissements d'enseignement et de recherche français ou étrangers, des laboratoires publics ou privés. 


\section{Lagrangian-based simulations of hypervelocity impact experiments on Mars regolith proxy}

M. Froment ${ }^{1,2}$, E. Rougier ${ }^{2}$, C. Larmat ${ }^{2}$, Z. Lei $^{2}$, B. Euser ${ }^{2}$, S. $\operatorname{Kedar}^{4}$, J. E. Richardson $^{3}$, T. Kawamura ${ }^{5}$, and P. Lognonné ${ }^{5}$

${ }^{1}$ École Normale Supérieure Paris-Saclay, Cachan, France

${ }^{2}$ Earth and Environmental Division, Los Alamos National Laboratory, New Mexico, USA

${ }^{3}$ Planetary Science Institute, Tucson, Arizona, USA

${ }^{4}$ Jet Propulsion Laboratory, California Institute of Technology, Pasadena, California, USA ${ }^{5}$ Université de Paris, Institut de physique du globe de Paris, CNRS, F-75005 Paris, France

\section{Key Points:}

- We conduct a parametric study of a novel Lagrangian numerical model of shock waves in granular media, with application to Mars regolith.

- We validate this model with a laboratory experiment in pumice sand with an impact velocity of $0.98 \mathrm{~km} / \mathrm{s}$.

- Amplitude of shock waves and transition to different regimes is explained by the model for the sensors placed vertically from the impact. 
An edited version of this paper was published by AGU. Copyright 2020 American Geophysical Union.

Froment, M., Rougier, E., Larmat, C., Lei, Z., Euser, B., Kedar, S., et al.. ( 2020). Lagrangian-based simulations of hypervelocity impact experiments on Mars regolith proxy. Geophysical Research Letters, 47, e2020GL087393. https://doi.org/10.1029/2020GL087393

\section{Abstract}

Most of the surface of Mars is covered with unconsolidated rocky material, known as re-golith. High-fidelity models of the dynamics of impacts in such material are needed to help with the interpretation of seismic signals that are now recorded by SEIS, the seis-mometer of InSight.

We developed a numerical model for impacts on regolith, using the novel Hybrid Optimization Software Suite (HOSS) which is a Lagrangian code mixing finite and dis-crete element formulations. We use data from hypervelocity impact experiments performed on pumice sand at the NASA Ames Vertical Gun Range to identify and calibrate key model parameters. The model provides insight into the plastic-elastic transition observed in the data and it also demonstrates that gravity plays a key role in the material response. Waveforms for receivers situated vertically below the impact point are correctly mod-eled, while more research is needed to explain the shallow receivers' signals.

\section{Plain Language Summary}

The generation of seismic waves by meteorite impacts in unconsolidated materials, such as Mars regolith, is a complex dynamic process. We present a numerical model based on a novel method and show its potential to explain the main characteristics of shock and seismic waves generated by impacts at laboratory scales. Our goal is to use this model to help with the analysis of data recorded during the InSight mission.

\section{Introduction}

InSight landed on Mars on November 26, 2018. Since then, the lander's robotic arm has placed a seismometer, the SEIS experiment, for the first time on the direct surface of the planet (Lognonné et al., 2019). SEIS is a single seismic station completed by pres-sure and wind sensors (Banfield et al., 2019). The absence of other stations to form a network can make the assessment of source distance and azimuth sometimes challenging based on the first SEIS observations (Lognonné et al., 2020; Giardini et al., 2020). Being able to identify signals produced by impacts would thus prove relevant to the mis-sion, as fresh craters can potentially be located by satellite imagery and provide a strong constraint on the source position (Daubar et al., 2018). Current estimations and mea-sures of impact rates on Mars show a higher frequency of craters smaller than 10m di-ameter, with 10 times more craters in the range of $[3.9,5.5] \mathrm{m}$ diameter created every 
year compared to craters of $[11,15.6] \mathrm{m}$ diameter (Teanby, 2015; Daubar et al., 2013; Malin et al., 2006). The expected rate of detection is estimated to about 8 impacts per year for the SEIS VBB (Banerdt et al., 2020), close to the pre-launch proposed rate (Lognonné \& Johnson, 2007; Daubar et al., 2018). The generation of seismic signals by such small events is dominated by the response of Mars regolith, a layer of unconsolidated rocky material covering the bedrock, which is supposedly desiccated at the InSight landing site close to Mars equator (Morgan et al., 2018). First analyses have confirmed low seismic velocities, which might even be as low as $120 \mathrm{~m} / \mathrm{s}$ for $\mathrm{P}$ waves at $0.5 \mathrm{~m}$ depth (Lognonné et al., 2020). Physic-based shock propagation codes allow high-fidelity modeling of the shock waves generated by meteorite impacts, which transition to seismic waves at further distances and thus control the shape and amplitude of the seismic signal that could be recorded by SEIS. Such modeling requires the codes to be able to track discontinuous features in time and space, like material fractures and phase transitions caused by the shock. Moreover, small impacts are expected to happen mostly in a solid regime of high viscosity, making the capture of non-isotropic processes an important requirement for simulation softwares.

Another challenge of modeling impacts in Mars regolith is its granular nature: friction and grain displacement processes in the material are important and grain interaction can lead to non-linear behaviors that manifest as "force-chains" (Sun et al., 2009; Gao et al., 2019) and "fairy-castle" structures (Hapke \& van Hoen, 1963; Carrier et al., 1991) depending on the confining stress on the grains. Moreover, the material is porous, which leads to an enhanced attenuation of shocks compared to bulk materials (Collins et al., 2019). Only now numerical methods to model impacts are starting to implement realistic, geologic materials as their target (Güldemeister \& Wünnemann, 2017; Pierazzo et al., 2008; Wünnemann et al., 2006). Here, we use the novel Lagrangian mechanical software HOSS, based on a finite-discrete element formulation (Munjiza, 2004; Munjiza et al., 2011, 2014, 2013; Lei et al., 2014), to create a new numerical model of impacts in regolith. The lagrangian framework is appropriately tackling all modeling challenges stated above, as it allows for a straightforward description of discontinuities in unconsolidated materials and deviatoric stresses. Consequently, a better description of shear waves and surface processes is possible as well as non-isotropic impact processes.

In the following, we present the laboratory experiments we use to validate the numerical model, as well as the numerical method and the material model used to describe 

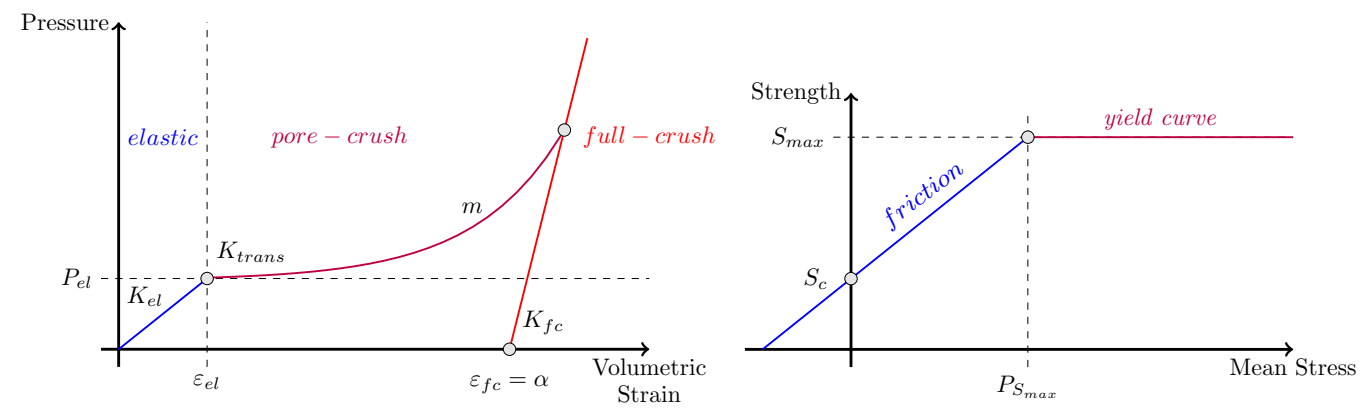

Figure 1. Simplified representation of the Equation of State (left) and the Strength Equation (right) and their key parameters.

Mars regolith. We present results of a parametric study of the model where we identify which parameters control the transition to the different regimes of impacts, meaning from shock to plastic to elastic response of the material. We then present a comparison of the model predictions to the laboratory data, before finishing with discussions and conclusions.

\section{Laboratory experiments and model.}

\subsection{Experiments}

The validation of the novel numerical model presented in this paper is done with data from a series of laboratory impact experiments conducted at the NASA/AVGR facility (Richardson \& Kedar, 2013). The experimental setup is composed of a cylindrical tank, 1 meter in radius and in height, filled with a target bed and placed inside a chamber with a controlled atmosphere. Tests were monitored by 15 accelerometers buried into the target at different positions. Sampling rate is $10^{-5} \mathrm{~s}$.

We focus on two experiments performed in an Earth atmosphere at Martian pressure of 5 to 10 torr, and on a target bed of pumice sand. This sand has a grain size of 0.1 to $0.2 \mathrm{~mm}$, a porosity of $62 \%$, and a composition and density similar to the Johnson Space Center (JSC) Mars-1 Regolith Simulant (Allen et al., 1997). In this study, the impactor is a $6.3 \mathrm{~mm}$ diameter bead with a mass of $0.29 \mathrm{~g}$ made of Pyrex, and an impact velocity of $0.98 \mathrm{~km} / \mathrm{s}$. 


\subsection{Numerical model}

The numerical model is based on a finite-discrete element representation (FDEM) used to handle the unconsolidated nature of Mars regolith. FDEM merges continuum solutions for the calculation of stresses as a function of deformation with the discrete element method for the resolution of fracture, fragmentation and contact interaction (Munjiza, 2004; Munjiza et al., 2011, 2014, 2013; Lei et al., 2014; Lei, Rougier, Knight, Munjiza, \& Viswanathan, 2016; Lei, Rougier, Knight, Frash, et al., 2016).

We generate meshes of tetrahedral elements covering a $30^{\circ}$ sector of the experiment tank. The numerical volume is $90 \mathrm{~cm}$ deep and wide and contains around 1,000,000 elements. Each Lagrangian finite element (FE) contains from approximatively 1000 grains of sand for the smallest ones close to the impactor (tetrahedrons of 1mm edges) and 1,000,000 grains of sand for the largest ones (tetrahedrons of $1 \mathrm{~cm}$ edges), allowing for a mesoscale representation of the sand properties.

To simulate the grain displacements involved in impacts in unconsolidated material, HOSS treats the tetrahedral FEs as an unconsolidated heap where the elements interact only through frictional contact, with a Coulomb coefficient of friction of 0.75 for this study. Inside each FE, the material model is governed by two equations, depicted in Figure 1. One describes the volumetric response, or Equation of State (EOS), and the other the deviatoric response, or Strength Equation (SE). The EOS is a function of pressure with volumetric strain and has three different domains. The first one is elastic, with pressure increasing linearly with strain, given a bulk modulus $K_{e l}$, as $P(\varepsilon)=K_{e l} \varepsilon$. After a limit pressure $P_{e l}$ is reached, the porous material undergoes grain displacement and grain crushing. This domain starts with a break of slope from $K_{e l}$ to $K_{\text {trans }}$ and is followed by an exponential increase of pressure with deformation. The equation of this curve is :

$$
P(\varepsilon)=P_{e l}+\frac{K_{\text {trans }}}{m \cdot \ln (10)}\left(10^{m\left(\varepsilon-\varepsilon_{e l}\right)}-1\right) \quad \text { for } \quad \varepsilon \geq \varepsilon_{e l} .
$$

where $\varepsilon$ is the strain, $\varepsilon_{e l}$ is the upper strain limit of the elastic regime and $m$ is a parameter describing the exponent of the curve. $K_{\text {trans }}$ drives the slope of the pore-crush curve at the beginning of the crushing processes. Given two values of $K_{\text {trans }}$, a lower value means that the material is easier to crush, because a lower amount of pressure is sufficient to obtain the same amount of deformation as with a higher value. $m$ is the expo- 
nent of the pore-crush curve and the same reasoning applies, i.e., a low $m$ results in an easily crushable material.

Finally, when the material is fully crushed and all the porosity $\alpha$ of the material disappears, the exponential curve morphs into a straight line with bulk modulus $K_{f c}$ of a non-porous rock of the same composition.

The SE (Figure 1, right) sets the limit deviatoric stress (i.e., yield stress) that can be sustained by the material for any given mean stress. In this simplified model, the yield curve first increases linearly with mean stress and upon reaching the yield limit $\left(P_{S_{\max }}, S_{\max }\right)$, it becomes constant, transitioning to a more viscous behavior. In the case of a granular material like sand, the cohesion $S_{c}$ of the material is zero.

The response of the impactor's material is represented using the Munjiza's elastic model (Munjiza et al., 2014; Lei, Rougier, Knight, Frash, et al., 2016). The FE size and impact speed result in an integration time step of a few nanoseconds. Given the time scale of the experimental signals, the simulation need to be run up to a few milliseconds.

\section{Results}

\subsection{Parametric study}

This work focuses on the parameters $K_{e l}, K_{\text {trans }}, m, P_{e l}$ and $P_{S_{\max }}$. For each of these parameters, between 3 and 4 simulations are run to explore the effect of their change on the shock wave properties. This first set of analysis is conducted without including Earth gravity to the simulation. The effects of this additional force are discussed in section 3.2 .

Literature on sand mechanical properties provide ranges of values for some of these parameters. The parameter $m$ thus seems to be between 3 and 6 for the sand studied in (Luo et al., 2011; Yamamuro et al., 1996, 2011). The elastic p-wave velocities measured on Mars regolith simulants (Morgan et al., 2018) range between $80 \mathrm{~m} / \mathrm{s}$ and 250 $\mathrm{m} / \mathrm{s}$ and the Poisson's ratio is around 0.2 , leading to $K_{e l}$ roughly between $5 \mathrm{MPa}$ and $60 \mathrm{MPa}$ for a bulk density of $880 \mathrm{~kg} / \mathrm{m}^{3}$. In many experiments (Berney IV \& Smith, 2008; Hyodo et al., 2002), the shear response of sands tends to remain in the domain of Coulomb friction even above a few MPa of pressure, leading to $P_{S_{\max }}>10^{6} \mathrm{~Pa}$. 


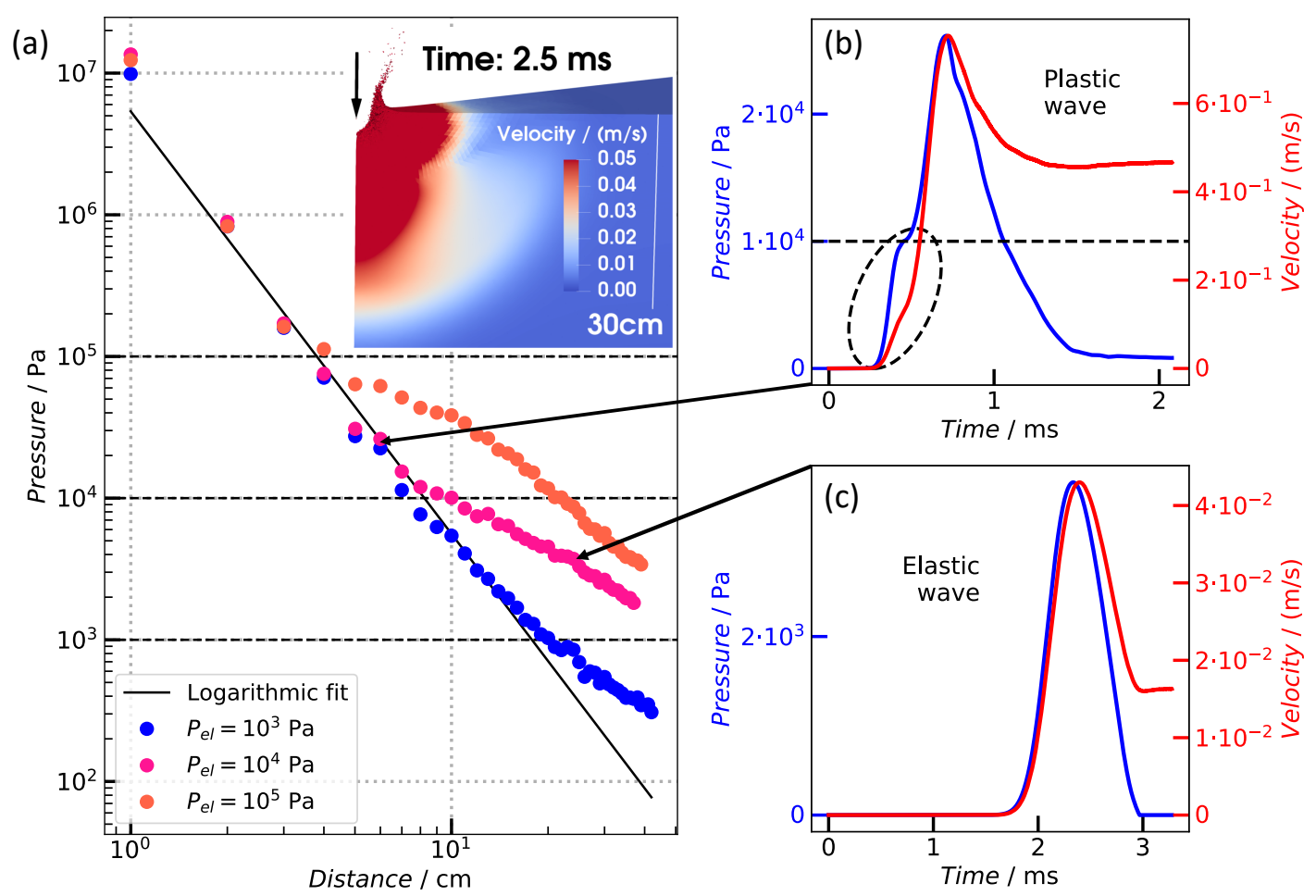

Figure 2. Evidence of an elastic and plastic regimes. (a) Shows the maximum modeled pressure recorded with distance for three different values of $P_{e l}$. In inset, a snapshot of a HOSS simulation of the $0.98 \mathrm{~km} / \mathrm{s}$ shot, showing the amplitude of the velocity and the ejected sand elements $2.5 \mathrm{~ms}$ after the impact. (b) Waveform in an area where $\mathrm{P}$ exceeds $P_{e l}=10^{4} \mathrm{~Pa}$. The dashed circle indicates the elastic precursor followed by the plastic wave. (c) Waveform in an area further away from the impact with only an elastic wave. $P_{e l}$ appears to be an important parameter controlling the transition between these two regimes. 
In a first test, $P_{S_{\max }}$ has been varied between $10^{6} \mathrm{~Pa}$ down to $10^{3} \mathrm{~Pa}$. For $P_{S_{\max }}>$ $10^{5} \mathrm{~Pa}$, the seismic waves show no visible change of amplitude, shape or velocity away from the impactor. Indeed, the stress values reached with these low-energy impacts are typically around $10^{4} \mathrm{~Pa}$. Only a few elements within $5 \mathrm{~cm}$ of the impact undergo pressures higher than $10^{6} \mathrm{~Pa}$. Therefore, the yield strength has to be lowered to very low values of $10^{4}$ or $10^{3} \mathrm{~Pa}$ to produce a visible effect on the shock wave away from the source. These values are far from typical values of yield strength measured for sand (Berney IV \& Smith, 2008) and can be considered unphysical, therefore the plastic wave is essentially unaffected by realistic yield strengths.

Consequently, we focus on the transition between elastic and plastic domain. It is known in shock physics that a deflection in the Shock-Hugoniot curve at the onset of plasticity results in the generation of two waves: the elastic precursor, which travels at elastic speed in the medium, and a plastic wave with slower propagation velocity and higher attenuation. These features are generated by the elastic-plastic transition in the EOS model, if $K_{\text {trans }}<K_{e l}$. This change of regime is evident on Figure 2 as a change of the slope of the evolution of the maximum pressure with distance. The break corresponds to the distance at which the maximum pressure falls below $P_{e l}$. Modeled signals for which the pressure exceeds $P_{e l}$ show an elastic precursor followed by a plastic wave, but contain only an elastic wave in the other case.

Table 1 gathers a series of measures on the effect of $K_{e l}$ and $K_{\text {trans }}$ on the impact shock wave. Four experiments were ran with $K_{e l}=G=10 \mathrm{MPa}$ and $K_{\text {trans }}$ varying between $\sim 1$ and $\sim 8 \mathrm{MPa}$. The velocity of the generated elastic wave was measured by picking the acceleration arrival times. As $K_{e l}>K_{\text {trans }}$, a plastic wave is also created, whose move-out velocity can be computed using the peak time of the pressure wave between sensors placed every $1 \mathrm{~cm}$. For our value of bulk modulus $K_{e l}$ and shear modulus $G$, the velocity of a purely acoustic wave is $v_{\text {accoustic }}=\sqrt{\frac{K_{e l}}{\rho}}=107 \mathrm{~m} / \mathrm{s}$, and the velocity of a solid P-wave is $v_{\text {solid }}=\sqrt{\frac{K_{e l}+\frac{4}{3} G}{\rho}}=162 \mathrm{~m} / \mathrm{s}$. The measured elasticwave velocity in the granular material is $v_{\text {accoustic }}<133 \mathrm{~m} / \mathrm{s}<v_{\text {solid }}$. Results show that the plastic wave itself propagates with a velocity slightly above $\sqrt{\frac{K_{\text {trans }}}{\rho}}$, but still slower than the measured elastic wave velocity. It also appears that, at a specific point in the tank, the ratio of pressure amplitude with the square root of $K_{\text {trans }}$ has a sim- 
Table 1. Parametric study of $K_{\text {trans }}$ (Runs 1 to 4 ) and $m$ (Runs 5 to 8). Plastic wave velocities have been measured by recording the time at which pressure peaks as a function of range. Elastic wave velocities have been measured by picking the acceleration wave arrival time with a threshold as a function of range. The theoretical value for this elastic wave velocity is between 107 and $162 \mathrm{~m} / \mathrm{s}$, as explained below. Peak pressure is also given at $20 \mathrm{~cm}$.

\begin{tabular}{|c|c|c|c|c|c|c|}
\hline Run & $\mathbf{m}$ & $\begin{array}{l}\mathbf{K}_{\text {trans }} \\
\text { (MPa) }\end{array}$ & $\sqrt{\frac{\mathbf{K}_{\text {trans }}}{\rho}}$ & $\begin{array}{c}\text { Plastic wave } \\
\text { velocity }(\mathrm{m} / \mathrm{s})\end{array}$ & $\begin{array}{c}\text { Elastic wave } \\
\text { velocity }(\mathrm{m} / \mathrm{s})\end{array}$ & $\begin{array}{l}\text { Peak pressure } \\
\text { at } 20 \mathrm{~cm}(\mathrm{kPa})\end{array}$ \\
\hline 1 & 5 & 7.9 & 95 & $94 \pm 1$ & $135 \pm 1$ & 5.15 \\
\hline 2 & 5 & 4.9 & 75 & $78 \pm 1$ & $133 \pm 1$ & 2.54 \\
\hline 3 & 5 & 2.8 & 58 & $61 \pm 1$ & $134 \pm 2$ & 1.57 \\
\hline 4 & 5 & 0.9 & 34 & $42 \pm 1$ & $138 \pm 2$ & 0.85 \\
\hline 5 & 6 & 1.5 & 40 & $51 \pm 1$ & $133 \pm 2$ & 1.01 \\
\hline 6 & 5 & 1.5 & 40 & $47 \pm 1$ & $134 \pm 2$ & 1.01 \\
\hline 7 & 4 & 1.5 & 40 & $45 \pm 1$ & $135 \pm 1$ & 0.97 \\
\hline 8 & 3 & 1.5 & 40 & $39 \pm 1$ & $136 \pm 1$ & 0.87 \\
\hline
\end{tabular}

ilar value for each experiment, suggesting a good agreement with a rough linear Hugoniot model of $P \sim V_{\text {impact }} \sqrt{K \rho}$.

To further analyse the effect of the pore-crush regime, the exponent $m$ of the porecrush curve is varied between 3 and 6 , while the parameter $K_{\text {trans }}$ is fixed to a value of 1.5 MPa, and we repeat the same measurement as before. In Table 1, our results show that, at the scale of these experiments, $m$ has only a moderate influence on the plastic wave velocity, as well as on the amplitude of the generated wave.

\subsection{Volumetric Response of Pumice Sand}

From the parametric study reported previously, it is possible to infer appropriate parameters to fit the experimental signals. To match the wave velocity measured on the vertical accelerometers of the AVGR shot, $K_{e l}$ is set to $10 \mathrm{MPa}$. The elastic precursor being visible up to $42 \mathrm{~cm}$ below the impact point in the experiments, $P_{e l}$ must be lower than the maximum pressure reached at this point, which leads to $P_{e l}=1 \mathrm{kPa}$. To match the amplitudes of the wave on each of the sensors, $K_{\text {trans }}$ is set to $6 \mathrm{MPa}$. The experimental data could not provide enough constraints on $m$ or the parameters from the SE. We thus set the exponent $m$ to 5 , a number found in some high-pressure experiments in several types of sands (Yamamuro et al., 1996, 2011; Luo et al., 2011). The SE yield point is set to a value of $1 \mathrm{MPa}$, too high to create any visible yield in our sand, and the 

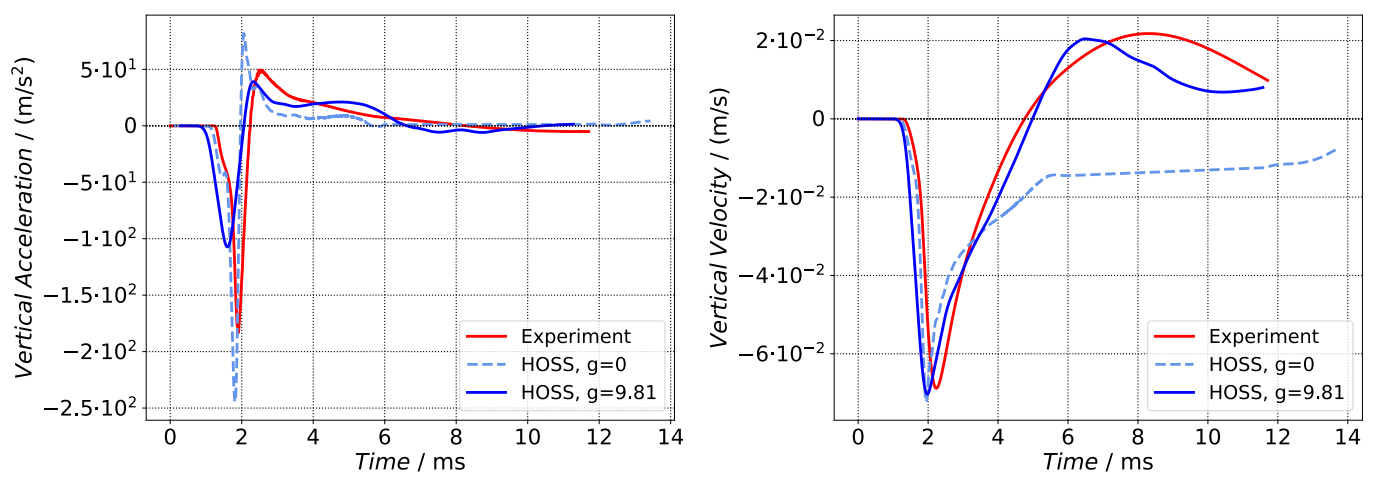

Figure 3. Compared numerical and experimental vertical acceleration (left) and velocity (right) signals for the $0.98 \mathrm{~km} / \mathrm{s}$ impact velocity shot, recorded at a sensor $21 \mathrm{~cm}$ directly below the impact point. The solid blue line and the dashed light-blue line correspond to simulations performed with and without earth gravity, respectively. The simulation better matches the experiment when gravity is considered.

friction coefficient is kept at 0.75 . To study the effects of gravity on the results, we include an initial acceleration of $-9.81 \mathrm{~m} / \mathrm{s}^{2}$ to one simulation, letting the sand relax to an equilibrium over a few $100 \mathrm{~ms}$ before the impact. Another simulation is run without gravity, but both use the same material model parameters as listed above. The resulting numerical and experimental waveforms are compared $21 \mathrm{~cm}$ directly below the impact point on Figure 3 and $30 \mathrm{~cm}$ horizontally from the impact point on Figure 4, both with and without the gravitational constraint.

On Figures 3 and 4, the modeled acceleration wave has an amplitude $40 \%$ lower and $33 \%$ higher than the experimental signal for the vertical sensor with and without gravity, respectively; and up to $100 \%$ higher for the horizontal sensor with no gravity. The velocity wave, however, ranges closer to the experimental signal. The arrival times at the vertical sensors match each other, in accordance with a measured vertical moveout velocity of $150 \mathrm{~m} / \mathrm{s}$. For the shallow sensors, we measure a horizontal move-out velocity closer to $80 \mathrm{~m} / \mathrm{s}$, while the modeled waves keep the same move-out velocity as for the vertical sensors, thus being ahead of time.

\section{Discussion, Conclusions and Future Work}

The presence of gravity improves significantly the modeled material response to the main shock. In the model without gravity, this response is weak enough so that the velocity of the vertical sensor remains negative after $5 \mathrm{~ms}$ (Figure 3 ). On the shallow sen- 
(a)

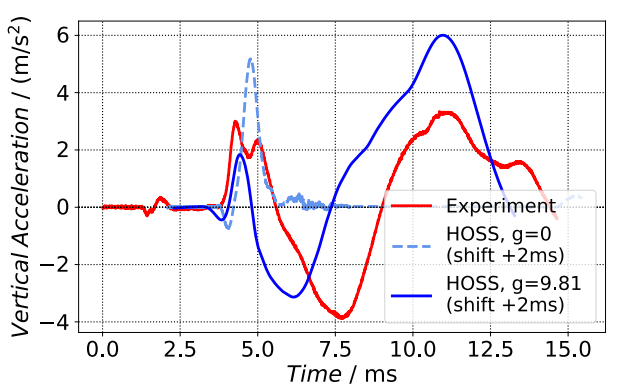

(b)

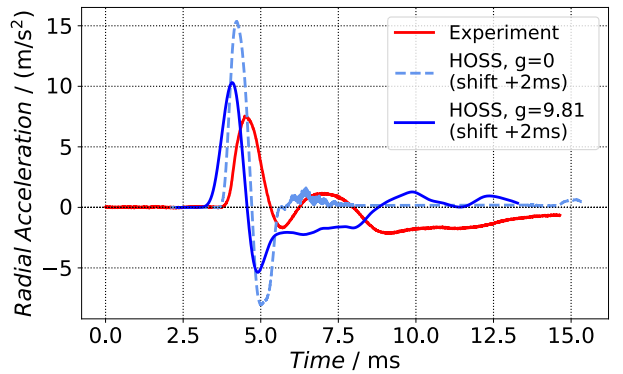

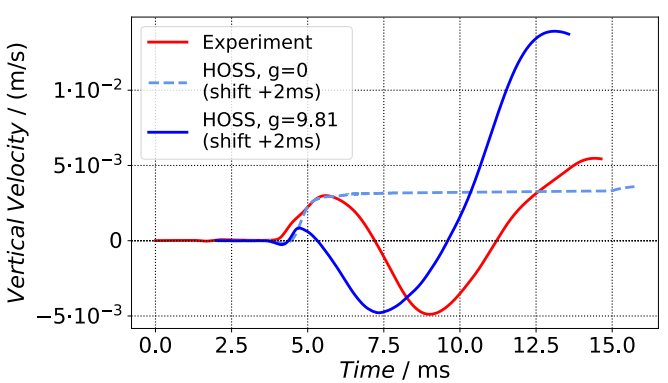

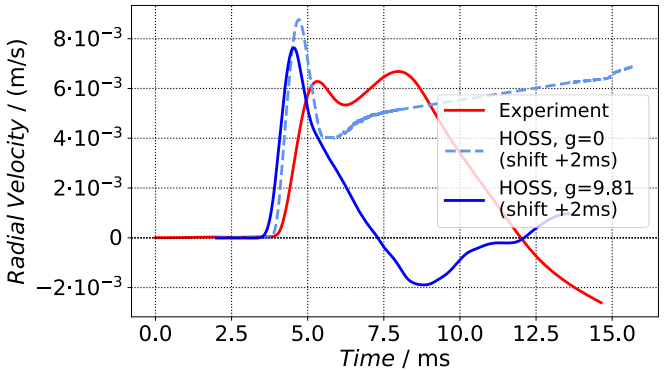

Figure 4. Compared numerical and experimental vertical (a) and radial (b) signals for the $0.98 \mathrm{~km} / \mathrm{s}$ impact velocity shot. Both accelerations and velocities are shown for the sensor $30 \mathrm{~cm}$ radially away from the impact point. The solid blue line and the dashed light-blue line correspond to simulations performed with and without earth gravity, respectively. Note that modeled signals have been shifted in time to obtain a better match (see text for details).

sor, the modeled velocity reaches a constant positive value after $4 \mathrm{~ms}$ when the acceleration vanishes (Figure 4). This indicates that the element attached to this sensor is in a non-accelerated motion, a "free-flight". The modeled signal with Earth gravity differ greatly. On Figure 3, we can see that the counter-response of the material to the impact is now strong enough to create a positive velocity on the vertical sensor, reproducing the behavior of pumice sand of the experiment. Acceleration on the shallow sensor displayed on Figure 4 doesn't show any longer evidence of free-flight but starts a cycle of falling down and rebounding as seen on the experimental data.

The parametric study suggests that the plastic yield, $P_{S_{\max }}$, has little influence on the shock wave. This is due to the fact that the stress level in our modeling reaches at most the order of $10 \mathrm{kPa}$, way lower than any documented plastic yield. The modeled material thus remains in a regime where the SE can be approximated by a simple MohrCoulomb surface. On the contrary, some questions remain on the effect of the elastic shear modulus $G$ of the material. In this study, $G$, which affects both the shear wave and Rayleigh wave speed of an elastic material, was fixed once it became clear that the main shock 
is mostly driven by the EOS parameters, but shear- or Rayleigh waves might still be an explanation for the late-time discrepancies between the modeled and experimental waves that are not caused by gravity. Moreover, this study shows that the wave move-out velocity is not completely determined by the elastic bulk modulus $K_{e l}$, but rather lies between the expected speed of sound in a fluid $v_{\text {accoustic }}$ and the P-wave velocity in a solid $v_{\text {solid }}$. A more thorough study of the influence of $G$ could shed some light on the elastic speed of waves in granular media, which can neither be considered as a fluid nor as a traditional elastic solid, and will help calibrating the model with respect to the experiments.

The study of the pore-crush curve suggests that plastic processes in sand, such as pore collapse and grain displacement are particularly efficient in the shock attenuation, and that the slope of the pore-crush curve of the EOS is key in capturing this attenuation. Still, trade-offs exist between the model parameters analyzed. For example, parameters $K_{\text {trans }}$ and $m$, that define the pore-crush curve, play a role in the amplitude and peak time of the plastic wave. An increase in $m$ could thus compensate for a decrease in $K_{\text {trans }}$. The low pressure part of the curve is easier to constrain with the available data, but the scale of the experiments does not allow for a proper determination of the highpressure response. The high-pressure EOS and SE will be of higher importance in the case of real planetary impacts, where the energy involved is several orders of magnitude higher. For example, the impact velocity distributions computed for Mars from observed asteroid populations yield a mean impact velocity of $9.6 \mathrm{~km} / \mathrm{s}$ (Ivanov, 2001). For better model accuracy at high pressures, other types of high-stress laboratory data or theoretical models should be considered in the future.

In conclusion, the final model captures the vertical wave's shape and amplitude for an impact velocity of $0.98 \mathrm{~km} / \mathrm{s}$. This proves that HOSS can reproduce the main characteristics of an impact shock wave in granular media. The results have shown to be more sensitive to variations on the EOS parameters than to variation on the SE parameters. Gravity has proved to be a key parameter in the later stages of wave simulation by providing a more realistic material response. However, the arrival times and amplitudes recorded at the shallow sensors cannot be reproduced by this model. Understanding this discrepancy requires further study, as a non-spherical wavefront needs to be modeled. Future works will investigate the effect of shear waves on the signal and the hypothesis of depthdependant elastic properties created by the constraint of sand by gravity, as it has al- 
ready been reported in literature (Morgan et al., 2018; van den Wildenberg et al., 2013). This non linear constraint creates a dependance of the bulk modulus with pressure in the elastic domain. Improving the fidelity of HOSS' model to the experimental truth will bring more insight into the physics of shocks in granular, highly porous media and a new definition of equivalent seismic sources for impacts. Such new validated modeling capability will help predict the signal of small planetary impacts, for which surface porous regolith endures most of the shock. These small impact might be recorded by InSight, if close enough, and provide new information on the crustal seismic properties of Mars.

\section{Acknowledgments}

This work is InSight contribution number 119 and LA-UR-19-32642. We thank the LANLHPC environment for providing and maintaining the Los Alamos High-Performance Computing facilities and the NASA/AVGR facility for conducting the impact experiments. We also thank the reviewers whose comments helped improve and clarify this manuscript. Experimental data are in the process of being transferred to an online repository. More details on the parametric study can be found in the Master thesis of the author (Froment, 2020). This work is funded by the LANL Center for Space and Earth Science (CSES) project XWPB00 and the ARPE student program of the École Normale Supérieure ParisSaclay. The French co-authors are acknowledging the support of CNES and ANR (under contract MAGIS ANR-19-CE31-0008-08).

\section{References}

Allen, C. C., Morris, R. V., Lindstrom, D. J., Lindstrom, M., \& Lockwood, J. (1997). JSC Mars-1-Martian regolith simulant. In Proceedings of the 28th lunar and planetary science conference. Retrieved from https:// www.lpi.usra.edu/meetings/lpsc97/pdf/1797.PDF

Banerdt, W. B., Smrekar, S. E., Banfield, D., Giardini, D., Golombek, M., Johnson, C. L., ... Wieczorek, M. (2020). Initial results from the InSight mission on Mars. Nature Geoscience. doi: https://doi.org/10.1038/s41561-020-0544-y

Banfield, D., Rodriguez-Manfredi, J. A., Russell, C. T., Rowe, K. M., Leneman, D., Lai, H. R., ... Banerdt, W. B. (2019). InSight Auxiliary Payload Sensor Suite (APSS). Space Science Reviews, 215(1), 4.

Berney IV, E. S., \& Smith, D. M. (2008). Mechanical and Physical Properties of ASTM C33 Sand (Tech. Rep.). US Army Engineer Research and Development Center, Geotechnical and Structures Laboratory.

Carrier, W. D., Olhoeft, G. R., \& Mendell, W. (1991). Physical properties of the lunar surface. Lunar sourcebook, 475-594.

Collins, G. S., Housen, K. R., Jutzi, M., \& Nakamura, A. M. (2019). Planetary impact processes in porous materials. In Shock phenomena in granular and porous materials (pp. 103-136). Springer.

Daubar, I., Lognonné, P., Teanby, N. A., Miljkovic, K., Stevanović, J., Vaubaillon, 
J., ... Banerdt, B. W. (2018). Impact-seismic investigations of the InSight mission. Space Science Reviews, $214(8), 132$.

Daubar, I., McEwen, A. S., Byrne, S., Kennedy, M., \& Ivanov, B. (2013). The current martian cratering rate. Icarus, 225(1), 506-516.

Froment, M. (2020). Internship Report: Numerical modelling of impact seismic signals on regolith. Office of Scientific and Technical Information. doi: https:// doi.org/10.2172/1593106

Gao, K., Guyer, R., Rougier, E., Ren, C. X., \& Johnson, P. A. (2019). From stress chains to acoustic emission. Physical review letters, 123(4), 048003.

Giardini, D., Lognonné, P., Banerdt, W. B., Pike, W. T., Christensen, U., Ceylan, S., ... Yana, C. (2020). The seismicity of Mars. Nature Geoscience. doi: https://doi.org/10.1038/s41561-020-0539-8

Güldemeister, N., \& Wünnemann, K. (2017). Quantitative analysis of impactinduced seismic signals by numerical modeling. Icarus, 296, $15-27$.

Hapke, B., \& van Hoen, H. (1963). Photometric studies of complex surfaces, with applications to the moon. Journal of Geophysical Research, 68(15), 45454570 .

Hyodo, M., Hyde, A. F., Aramaki, N., \& Nakata, Y. (2002). Undrained monotonic and cyclic shear behaviour of sand under low and high confining stresses. Soils and Foundations, 42(3), 63-76.

Ivanov, B. A. (2001). Mars/Moon cratering rate ratio estimates. Space Science Reviews, $96(1-4), 87-104$.

Lei, Z., Rougier, E., Knight, E., \& Munjiza, A. (2014). A framework for grand scale parallelization of the combined finite discrete element method in 2d. Computational Particle Mechanics, 1(3), 307-319.

Lei, Z., Rougier, E., Knight, E. E., Frash, L., Carey, J. W., \& Viswanathan, H. (2016). A non-locking composite tetrahedron element for the combined finite discrete element method. Engineering Computations.

Lei, Z., Rougier, E., Knight, E. E., Munjiza, A., \& Viswanathan, H. (2016). A generalized anisotropic deformation formulation for geomaterials. Computational Particle Mechanics, 3(2), 215-228.

Lognonné, P., Banerdt, W., Pike, W., Giardini, D., Christensen, U., Garcia, R., ... Zweifel, P. (2020). Constraints on the shallow elastic and anelastic structure of Mars from InSight seismic data. Nature geoscience. doi: http://doi.org/10.1038/s41561-020-0536-y

Lognonné, P., Banerdt, W. B., Giardini, D., Pike, W. T., Christensen, U., Laudet, P., ... Wookey, J. (2019). SEIS: Insight's Seismic Experiment for Internal Structure of Mars. Space Science Reviews, 215(1), 12.

Lognonné, P., \& Johnson, C. L. (2007). Planetary seismology. Treatise on Geophysics, 10, 69-122.

Luo, H., Lu, H., Cooper, W. L., \& Komanduri, R. (2011). Effect of mass density on the compressive behavior of dry sand under confinement at high strain rates. Experimental mechanics, 51(9), 1499-1510.

Malin, M. C., Edgett, K. S., Posiolova, L. V., McColley, S. M., \& Dobrea, E. Z. N. (2006). Present-day impact cratering rate and contemporary gully activity on mars. science, $314(5805), 1573-1577$.

Morgan, P., Grott, M., Knapmeyer-Endrun, B., Golombek, M., Delage, P., Lognonné, P., ... Kedar, S. (2018). A pre-landing assessment of regolith properties at the InSight landing site. Space Science Reviews, 214(6), 104.

Munjiza, A. (2004). The combined finite-discrete element method. John Wiley \& Sons.

Munjiza, A., Knight, E. E., \& Rougier, E. (2011). Computational mechanics of discontinua. John Wiley \& Sons.

Munjiza, A., Knight, E. E., \& Rougier, E. (2014). $\quad$ Large Strain Finite Element Method: A Practical Course. John Wiley \& Sons. 
Munjiza, A., Rougier, E., Knight, E. E., \& Lei, Z. (2013). $\quad$ HOSS: An integrated platform for discontinua simulations. In G. Chen, Y. Ohnishi, L. Zheng, \& T. Sasaki (Eds.), Frontiers of discontinuous numerical methods and practical simulations in engineering and disaster prevention (pp. 97-104). CRC Press. Retrieved from https://doi.org/10.1201/b15791-12

Pierazzo, E., Artemieva, N., Asphaug, E., Baldwin, E. C., Cazamias, J., Coker, R., ... Wünnemann, K. (2008). Validation of numerical codes for impact and explosion cratering: Impacts on strengthless and metal targets. Meteoritics $\&$ Planetary Science, 43(12), 1917-1938.

Richardson, J., \& Kedar, S. (2013). An experimental investigation of the seismic signal produced by hypervelocity impacts. In Lunar and planetary science conference (Vol. 44, p. 2863).

Sun, Q., Wang, G., \& Hu, K. (2009, 05). Some open problems in granular matter mechanics. Progress in Natural Science - PROG NAT SCI, 19. doi: 10.1016/ j.pnsc.2008.06.023

Teanby, N. (2015). Predicted detection rates of regional-scale meteorite impacts on Mars with the InSight short-period seismometer. Icarus, 256, 49-62.

van den Wildenberg, S., van Loo, R., \& van Hecke, M. (2013). Shock waves in weakly compressed granular media. Physical review letters, 111(21), 218003.

Wünnemann, K., Collins, G., \& Melosh, H. (2006). A strain-based porosity model for use in hydrocode simulations of impacts and implications for transient crater growth in porous targets. Icarus, $180(2), 514-527$.

Yamamuro, J. A., Abrantes, A. E., \& Lade, P. V. (2011). Effect of strain rate on the stress-strain behavior of sand. Journal of Geotechnical and Geoenvironmental Engineering, 137(12), 1169-1178.

Yamamuro, J. A., Bopp, P. A., \& Lade, P. V. (1996). One-dimensional compression of sands at high pressures. Journal of geotechnical engineering, 122(2), 147154 . 